\title{
Conceptions of Learning and Understanding Learning at Work
}

\author{
Paul Hager \\ University of Technology, Sydney
}

\begin{abstract}
Recent research on learning in work situations has focussed on concepts such as 'productive learning' and 'pedagogy of vocational learning'. In

investigating what makes learning productive and what pedagogies enhance this, there is a tendency to take the notion of learning as unproblematic. This paper argues that much writing on workplace learning is strongly shaped by peoples' understandings of learning in formal educational situations. Such assumptions distort attempts to understand learning at work. The main focus of this paper is to problematise the concept of 'learning' and to identify the implications of this for attempts to understand learning at work and the conditions that enhance it. An alternative conception of learning that promises to do more justice to the richness of learning at work is presented and discussed.
\end{abstract}

For several years now, the adult and vocational learning research group at University of Technology, Sydney, (now known as OVAL Research ${ }^{1}$ ), has been pursuing a systematic research agenda centred on issues about learning at work (e.g. Boud \& Garrick 1999, Symes \& McIntyre 2000, Beckett \& Hager 2002). The OVAL research group's two most recent seminar series have been focussed on 'productive learning' and 'pedagogy of vocational learning'. Both of these topics reflect a concern with conditions that enhance rich learning in work situations. In attempting, however, to characterise what makes learning productive and what pedagogies enhance this, there may be a tendency to take the notion of learning as unproblematic. I have elsewhere argued that common understandings of learning uncritically incorporate assumptions that derive from previous formal learning experiences (Hager forthcoming). Likewise Elkjaer (2003) has recently pointed out how much writing on workplace learning is strongly shaped by the authors' understandings of learning in formal educational situations. The main focus of this paper is to problematise the concept of 'learning' and to identify the implications of this for attempts to understand learning at work and the conditions that enhance it. A key claim is that government policies that impact significantly on learning at work commonly treat learning as a product, i.e. as the acquisition of discrete items of knowledge or skill. The argument is that these policies thereby obstruct attempts to develop satisfactory understandings of learning at work.

\footnotetext{
${ }^{1}$ The Australian Centre for Organisational, Vocational and Adult Learning Research. (For details see www.oval.uts.edu.au)
} 


\section{Problematising the Concept of Learning}

Although learning is still widely treated as an unproblematic concept in educational writings, there is growing evidence that its meaning increasingly is being contested. For instance Brown \& Palincsar (1989, p. 394) observed: "Learning is a term with more meanings that there are theorists". Schoenfeld $(1999$, p. 6) noted "....that the very definition of learning is contested, and that assumptions that people make regarding its nature and where it takes place also vary widely." According to Winch ".....the possibility of giving a scientific or even a systematic account of human learning is .... mistaken" (1998, p. 2). His argument is that there are many and diverse cases of learning, each subject to "constraints in a variety of contexts and cultures" which precludes them from being treated in a general way $(1998$, p. 85). He concludes that "... grand theories of learning .... are underpinned ... invariably ... by faulty epistemological premises" (Winch, 1998, p. 183).

Not only is the concept of learning disputed amongst theorists, it seems that even those with the greatest claims to practical knowledge of learning may be deficient in their understanding. Those bastions of learning, higher education institutions can trace their origins back into the mists of time. If anyone knows from experience what learning is it should be them. Yet the recent cyber learning debacle suggests otherwise. Many of the world's most illustrious universities have invested many millions of dollars setting up suites of online courses in the expectation of making large profits from offcampus students. According to Brabazon (2002), these initiatives have manifestly failed since prospective students were not prepared to pay the fees. Many of these online courses are now available free as a backup resource for on-campus students. Brabazon's analysis is that these university 'experts' on learning have confused technology with teaching and tools with learning. The staggering sums of money mis-invested in online education certainly shows that universities may not be the experts in learning that they think they are.

We can take Brabazon's analysis a step further. The reason why tools were confused with learning, I argue, is that learning is not a well understood concept at the start of the $21^{\text {st }}$ century. Perhaps it is in a similar position to the concept of motion at the end of the middle ages. Of course, motion is one of the central concepts in physics, just as learning is a central concept in education, and the social sciences generally. For a long time, understanding of motion was limited by adherence to the Aristotelian attempt to provide a single account of all motion. Aristotle proposed a second-order distinction between natural and violent motions. It was the 'nature' of all terrestrial bodies to have a natural motion towards the centre of the universe (the centre of the earth); but bodies were also subject to violent motions in any direction imparted by disruptive, external, 'non-natural' causes. So the idea was to privilege one kind of motion as basic and to account for others in terms of non-natural disruptions to this natural motion. The Aristotelian account persisted for so long because it was in accord with 'common sense' ideas on 
motion. Everyone was familiar with motion and thought that they understood it. Likewise, everyone has experienced formal schooling and this shapes how they understand learning. Thus, the type of learning that is familiar to everyone gains privileged status. The worth of other kinds of learning is judged by how well they approximate the favoured kind (Beckett \& Hager 2002, section 6.1). The dominance of this concept of learning is also evident in educational thought, where there has been a major focus on learning in formal education settings. This dominant view of learning also fits well with 'folk' conceptions of the mind (Bereiter 2002).

Real progress in understanding motion came when physicists departed from 'common sense' ideas and recognised that there are many different types of motion - falling, projectile, pendulum, wave, etc. - each requiring their own account. Likewise, it seems there are many types of learning and things that can be learnt - propositions, skills, behaviours, attitudes, etc. Efforts to understand these may well require a range of theories each with somewhat different assumptions.

\section{The Monolithic Influence of Viewing Learning as a Product}

There is currently a dominant view of learning that is akin to the Aristotelian view of motion in its pervasive influence. It provides an account of supposedly the best kind of learning, and all cases of learning are judged by how well they fit this view. This dominant view of learning - the 'common sense' account - views the mind as a 'container' and 'knowledge as a type of substance' (Lakoff \& Johnson 1980).

Under the influence of the mind-as-container metaphor, knowledge is treated as consisting of objects contained in individual minds, something like the contents of mental filing cabinets.

(Bereiter 2002, p. 179)

Thus there is a focus on 'adding more substance' to the mind. This is the 'folk theory' of learning (e.g. Bereiter 2002). It emphasises the products of learning.

At this stage it might be objected that the educationally sophisticated have long ago moved beyond viewing learning as a product. Certainly, as shown later in this paper, the educational arguments for an alternative view have been persuasive for quite some time now. Nevertheless, much educational policy and practice, including policies and practices that directly impact on the emerging interest in learning at work, are clearly rooted in the learning as product view. For instance, typical policy documents relating to CompetencyBased Training view work performance as a series of decontextualised atomic elements, which novice workers are thought of as needing to pick up one by one. Once a discrete element is acquired, transfer or application to appropriate future circumstances by the learner is assumed to be unproblematic. This is a pure learning as product approach. Similarly, policy documents on generic skills (core or basic skills) typically reflect similar assumptions. Putative generic skills, such as communication and problem 
solving, are presented as discrete, decontextualised elements that, once acquired, can simply be transferred to diverse situations. Certainly, in literature emanating from employer groups, this assumption is endemic. These, then, are two policy areas that are closely linked to learning at work that are dominated by learning as product assumptions.

Of course, Lyotard (1984) and other postmodern writers (e.g. Usher \& Edwards 1994) have argued that the recent neo-liberal marketisation of education results in a commodification of knowledge, in which knowledge is equated with information. Such information can, for instance, be readily stored and transmitted via microelectronic technology. Students become consumers of educational commodities. All of this is grist to the learning as product mill. However, it needs to be emphasised that learning as product was the dominant mindset long before the rise of neo-liberal marketisation of education. This is reflected in standard international educational nomenclature: acquisition of content, transfer of learning, delivery of courses, course providers, course offerings, course load, student load, etc. So despite advances in educational thought, the learning as product view has remained very resilient. It is as though formal education systems have never gotten beyond a mass production mindset reminiscent of the industrial era.

The dominant learning as product view involves two basic assumptions. The stability assumption, which requires the products of learning to be relatively stable over time. This stability enables learning to be incorporated into curricula and textbooks, to be passed on from teachers to students, its attainment to be measured in examinations, and the examination results for different teachers and different institutions to be readily amenable to comparison. Thus formal education systems depend for assessment purposes on learning that is stable, familiar and widely understood. Engestrom puts this assumption of what he calls 'standard theories of learning' as follows: 'a self-evident presupposition that the knowledge or skill to be acquired is itself stable and reasonably well-defined' (Engestrom 2001, p. 137). As well, there is a replicability assumption - that the learning of different learners can be literally the same or identical. The sorting and grading functions of education systems requires the possibility of this kind of foundational certainty of marks and grades. These matters are reflected in the common term used to denote replicability of learning - different students are said to have the same 'attainment' (something like two filing cabinets having identical contents).

The pervasive influence of the 'learning as product' view can perhaps be thought of in terms of Bourdieu's concept of habitus. For Bourdieu (1990b), habitus is a kind of socialised subjectivity, that is socially acquired, embodied systems of dispositions. As such, they represent a fine balance between structure and agency:

Agents to some extent fall into the practice that is theirs rather than freely choosing it or being impelled into it by mechanical constraints.

(Bourdieu, 1990b, p. 90) 
The suggestion is that 'learning as product', as socially acquired habitus, is not immutably entrenched. However, change is possible only to the extent that the wider social forces that transmit it are themselves altered.

\section{Difficulties Flowing from Viewing Learning as a Product}

If there are indeed many kinds of learning, as suggested earlier, then it will not be surprising that the monotheoretical account faces a growing number of difficulties. Four particular difficulties for the 'learning as a product' view are discussed below.

\section{Failures of theory/practice accounts of performance}

Theory / practice accounts of work performance are based on what Schön (1983) calls "technical rationality". This is the view that practitioners use their disciplinary knowledge to analyse and solve the work problems that their daily practice throws up. According to Altrichter, Posch \& Somekh (1993), the three main assumptions of technical rationality, or the theory/practice account, are:

- There are general solutions to practical problems.

- These solutions can be developed outside practical situations (in research or administrative centres).

- The solutions can be translated into practitioners' actions by means of publications, training, administrative orders, etc.

But the world of actual practice is much messier than this tidy schema suggests. For one thing, ready-made problems do not simply present themselves to the practitioner. The implications for the theory/practice approach are, seemingly, fatal. As Beckett \& Hager (2002, p. 132) put it:

..... the difficulty for technical rationality is not just that problems are not presented ready-made, and that, therefore, practitioners need to become proficient in problem-setting. Once a problem has been specified, it may not fit standard applied science categories. So both the data required and the solution method may be unclear. As well, the problem situation may be unique or unstable. This may require that the problem be continually redefined.

Bourdieu (1990a) indirectly attacks the theory/practice account, by making a distinction between two logics: the logic of practice and the logic of the theorisation of practice. He sees a strong tension between the two, between the logic of practice which is situated, contextual, embodied and tacit, and the logic of the theorisation of practice which centres on generality, abstraction and logical reasoning. Bourdieu's critique is that "the logic of practice can only be grasped through constructs which destroy it as such." (1990a, p. 11). While accepting that there is a tension here, my response is that the gap may not be so unbridgeable. Rather, the logic of the theorisation of practice has focussed on the wrong concepts, ones that bring with them unacceptable assumptions such as 'practice is application of theory'. Hence theoretical 
accounts of practice have failed because they drew on the wrong concepts. Better concepts that involve more relevant assumptions might yet produce a conceptual understanding of practice.

\section{Failures of the front-end model of vocational preparation}

The 'learning as product' view underpins the front-end model of vocational preparation, a model being questioned increasingly for its failures. The term 'front- end' refers to models of vocational preparation that require a period of formal education and/or training that needs to be completed by entrants to an occupation before they can be regarded as qualified workers. This period of formal education and/or training usually takes place in classrooms remote from the workplace (Beckett and Hager 2002, p. 99). But, most importantly, this model is called 'front- end' " .... because it implies that all of the learning that is needed for a lifetime of practice has been completed" (Beckett and Hager 2002, p. 99). The perceived failures of the front-end model of vocational preparation are of various kinds. These include:

- the increasing realisation that front-end courses in themselves are insufficient to prepare novices for a lifetime of practice. (For one thing, practice invariably involves components of tacit knowledge or 'knowhow' that cannot be acquired in formal settings remote from practice. So some suitable experience of real practice is necessary to attain proficiency as a practitioner.)

- the growing rejection of the technical-rationality assumption (see above) that underpins many front-end vocational preparation courses.

- growing doubts about the capacity of the front-end model to prepare practitioners for accelerating change.

(For more discussion of these see Beckett \& Hager, 2002, pp. 101-5).

A further reason to question the efficacy of the front-end model of vocational preparation stems from a range of research on learning in higher education. Although this research is mainly focussed on learning in undergraduate courses, there is no reason to doubt that the findings would apply generally to front-end vocational preparation courses of all kinds. This phenomenographic research on learning in higher education has led practitioners to centre on concepts such as surface vs. deep approaches to learning. This research has found that much learning in higher education settings is far from optimal (e.g. see Bowden \& Marton 1998, Prosser \& Trigwell 1999). A typical finding is that “.... despite students' having successfully negotiated the assessment system, little understanding of fundamental concepts has been gained" (Bowden \& Marton 1998, p. 61). This clearly signals a failure of the assumptions of the front-end model of vocational preparation. The supposed discrete bit-by-bit acquisition of learning products is simply not happening. This is alarming for those who adhere to a learning as product view. However, if learning is viewed as a process, as assumed by the emerging view of learning outlined later in this paper, these findings may be less unexpected. If learning a traditional discipline is a gradual process of growing understanding, rather than discrete 
bit-by-bit mastery, then perhaps key conceptual development will remain incomplete even after several years of intense study. This would suggest that rather than viewing learning as atom-by-atom acquisition of content, a better image to represent the gaining of high level proficiency in a discipline might be something like the 'gradual clearing of a fog in a landscape'. Thus, rather than concept acquisition being thought of as an all-or-nothing learning event, it might be better understood as something that grows over time for the learner. During this process of concept acquisition within a discipline or field, the import of a range of central concepts gradually deepens for the learner, as does an appreciation of the links between the various concepts.

\section{Denigration of learning}

The wide acceptance of the 'learning as a product' view extends to the workplace. Educators, of course, use terms like 'learner' and 'learning' in either approving or relatively neutral ways. It is regarded as unproblematic that learning is usually a good thing. Similar approbation is implied when workplace educators deploy such terms as workplace learning, lifelong learning, and organisational learning. But as research reported by Boud \& Solomon (2003) suggests, in workplaces not too far removed from the academy, unconscious commitment to the learning as product view leads people to assign negative connotations to terms such as 'learner' and 'learning'. These terms are viewed negatively because they seem to conflict with workers' overall perception of their identity and status within the organisation. It is precisely because of the dominant learning as product view that in the community at large, being a learner can be seriously problematic. On the product view of learning a learner is someone who has yet to acquire all of the requisite products or mental items for carrying out the work. Thus to be a learner in the workplace on this view is:

- to have a deficit, e.g. to be inexperienced or incompetent.

- to therefore have less power, position, recognition, or legitimation.

- to need to leave behind the role of 'learner' as quickly as possible (the 'L plate' syndrome).

Hence, there are also perceived tensions in people being given dual labels by workplace educators or theorists, e.g. being both a 'worker' and a 'learner' or a 'professional' and a 'learner', at the same time. The moral of all this is that the terms 'learner' and 'learning' do different work in different contexts. The act of naming someone (especially oneself) as a learner can be controversial. Though Boud \& Solomon found that the act of naming something as learning is usually somewhat less controversial. Overall, though, as this research demonstrates, the ongoing influence of the dominant learning as product view is still evident in workplaces.

\section{$4 \quad$ Lifelong learning is viewed as odd and unattractive}

The learning as product view clearly has unattractive implications for thinking about lifelong learning. For a start it suggests endless accumulation of discrete pieces of learning. One imagines over-crammed filing cabinets. If 
learning is centrally about minds acquiring propositions, lifelong learning is potentially about perpetual enrolment in formal accredited courses. The individual learner is in danger of being condemned to learn all subjects/disciplines. In this respect, part of the 'folk theory' of learning is an acceptance of a 'quiz show' view of what it is for someone to be learned. (This contrasts with the Socratic view that the more you 'know', the more you know that you don't know). As well, the focus here is firmly on the individual learner. Illich (1973) was right that we have been schooled to accept a 'consumer of formal courses' view of knowledge acquisition. In addition, if the concept of 'learning' sometimes carries in the workplace the negative connotations identified by Boud \& Solomon above, these will equally tarnish the notion of 'lifelong learning'. In that case, the idea of lifelong learning at work will be distinctly unpalatable. This is not to deny that lifelong learning discourse has had some success in changing peoples' understandings of 'learning'. However, the ongoing influence of the dominant learning as product view will certainly reduce the efficacy of that discourse.

\section{Theoretical Responses to These Difficulties}

A number of recent theoretical developments reflect growing disenchantment with the 'learning as a product' view. These include:

\section{New directions in psychology}

There is a clear move away from the idea that learning is paradigmatically a mind being stored with contents (e.g. Bruner 1996, Bereiter 2002). As Bereiter puts it:

... everyday cognition makes more sense if we abandon the idea of a mind operating on stored mental content and replace it with the idea of a mind continually and automatically responding to the world and making sense of whatever befalls it. I call this the 'connectionist view of mind'...

(Bereiter 2002, pp. 196-7).

Connectionism provides an alternative metaphor, which enables us to conceive of a mind that can act knowledgeably without containing propositions or other knowledge objects. To gain benefit from the connectionist metaphor, we must find ways to construct mentalistic accounts that do not refer to things residing, being searched for, or undergoing changes in the mind. (Bereiter 2002, pp. 179).

\section{Learning transfer research}

Learning transfer research has led to recent proposals to reconceptualise transfer and, by implication, learning. Researchers see the institution of formal education being underpinned by the basic assumption that transfer is a ubiquitous phenomenon. However despite increasing power of experimental techniques, transfer "seems to vanish when experimenters try to pin it down" (Schoenfeld 1999, p. 7). As Bransford \& Schwartz (1999) point out, transfer is indeed rare if it is restricted to 'replicative' transfer, which involves both the stability and replicability assumptions that were noted 
above. However, they propose that we broaden the notion of 'transfer' by including an emphasis on 'preparation for future learning', the ability to learn in new environments. This proposal is very consistent with the idea of learning as a process and the emerging view of learning, which are discussed in the next section. So the point of transfer is not replication. They suggest this broader notion is 'knowing with' rather than 'knowing that' (replicative) or 'knowing how' (applicative).

\section{The Emerging View of Learning}

As various points discussed so far suggest, there is a problem with regarding learning as the acquisition of discrete items that can then be called up at will. With regard to each distinct item, the implication is that, once acquired, the learning with respect to that item is complete. Rather, as much of the above discussion suggests, learning might be viewed more fruitfully as an ongoing process. Dewey (1916) was an early seminal figure in educational thought who saw learning as a process. For Dewey, the overriding principle is that the good life for humans is one in which they live in harmony with their environment. But because the environment is in a state of continuous flux, so humans need to grow and readjust constantly to it so as to remain in harmony with it. Thus, for Dewey, education must instil the lifelong capacity to grow and to readjust constantly to the environment. Since, argued Dewey, reflective thinking as well as inquiry, democracy, problem solving, active learning, experiential learning, etc. are methods that are necessary for humans to learn to readjust effectively to the environment, these are the teaching/learning methods that must feature in education. Dewey argues that reflection is central to effective inquiry and problem solving, but this should not be seen merely in narrowly rational terms. For Dewey, reflective thinking is more holistic, incorporating social, moral and political aspects of the contexts in which it occurs.

Dewey can be regarded as a pioneer of the conception of learning as a process (or, more accurately, as a dialectical interplay of process and product). The sharp distinction between process and product of learning is plausible whenever learning is separated from action. However, when learning is closely linked with action, the two are not sharply distinguished at all. The process facilitates the product which at the same time enhances further processes and so on. (While bearing in mind the dialectical interplay of process and product, in the following I will refer to 'learning as process' for the sake of simplicity). Even in his lifetime Dewey's ideas were widely noted and discussed. However they can hardly be said to have transformed educational thought, let alone practice, as the ongoing persistence of the dominant metaphor of learning as a product shows. However, various recent developments in educational thought have brought the notion of learning as a process into new prominence. Bereiter's connectionist view of the mind as an entity that continually and automatically responds to the world, making sense of whatever befalls it, is an example. Likewise, the Bransford \& Schwartz concept of 'preparation for future learning' centres on learning as a process 
rather than as a product. More generally, the two most influential contemporary approaches to understanding learning centre on viewing it as a process. Firstly, there are the sociocultural theorists, such as Lave and Wenger (1991) and Wertsch (1998). This approach focuses on processes rather than entities or structures, and stresses the inseparability of the individual and the social. Secondly, there is activity theory, a type of theorising originally inspired by the work of Vygotsky and Leont'ov, and developed by Engestrom and others (e.g. Engestrom, Miettinen \& Punamaki 1999, Engestrom 2001). This approach produces dynamic accounts of human activity, including learning, that emphasise its mediation by tools (understood in the broadest sense). Taken together, these trends in educational thought support the claim that learning as a process is the emerging view of learning.

When learning is viewed primarily as a process rather than as a product different features are emphasised. Learning becomes a process that changes both the learner and the environment (with the learner being part of the environment rather than a detached spectator) (Beckett \& Hager 2002 section 7.9). This view of learning underlines its contextuality, as well as the influence of cultural and social factors. It is holistic in that it points to the organic, whole person nature of learning, including the importance of dispositions and abilities. Viewing learning as a process also has some positive consequences that counter the unfortunate implications of viewing it as a product (outlined earlier). If learning is seen as an ongoing process, then:

- Learning is a normal and desirable thing, since its ends are never really reached.

- Lifelong learning is usual, and even inevitable for humans. At its best informal learning is a key part of lifelong learning. The social and contextual aspects of learning gain their rightful emphasis.

Another important aspect of the emerging view of learning is that it accounts better for the phenomenon of tacit knowledge. The learning as product view, with its focus on knowledge as relatively stable, well-defined propositions, regards the tacit (literally that which cannot be put into words) with suspicion. For the learning as product view, the best kind of learning is transparent. So, at best, tacit knowledge is a dubious kind of learning. However, once our understanding of learning centres on the human capacity to grow and to readjust constantly to the environment, much important learning is seen to be inescapably tacit. The human capacity to grow and thrive in an environment is underpinned by a diversity of attributes, such as capabilities, abilities, and skills, that cannot be precisely specified. Our inability to provide a precise characterisation of many of our important capabilities, abilities, and skills was famously noted by Polanyi:

I shall reconsider human knowledge by starting from the fact that we can know more than we can tell. This fact seems obvious enough; but it is not easy to say exactly what it means. Take an example. We know a person's face, and can recognise it among a thousand, indeed among a 
million. Yet we usually cannot tell how we recognise a face we know. So most of this knowledge cannot be put into words. (1983, p. 4)

And, of course, this argument applies to not just our knowledge of human capabilities, abilities, and skills. Much of human experience is meaningful in ways that elude precise linguistic formulation. As Magee put it:

.... the most important to us of our dispositions cannot be put into words ... - being in love, for example, or our feeling for our friends, or what music means to us in our lives, or our relationship with our children, or our passion for philosophy (come to that a passion for anything, even golf).

(Magee 1998, p. 99)

Passmore (1980) has drawn attention to the educational importance of the often overlooked capacities and dispositions that are presupposed by other types of learning. His examples include: learning to- walk, run, speak, read, write, and add. According to Passmore (1980, p. 37) such capacities are a major, perhaps the major, class of human learning. For Passmore in normal cases ".... every human being acquires a number of capacities for action ..... whether as a result of experience, of imitation or of deliberate teaching....". Likewise, Winch (1998, p. 19) argues that knowledge is largely dispositional. Overall, the transparency of learning assumption, favoured by the learning as product view, is challenged by the increasing recognition of the importance of non-transparent types of learning, one of which, dispositional learning, is presupposed by other forms of learning.

The following definitions highlight the contrasts between the product and process views of learning. According to the Oxford English Dictionary, learning means: 'To acquire knowledge of (a subject) or skill (an art, etc.) As a result of study, experience or teaching.' Besides portraying learning as a product, this definition is in danger of limiting learning to propositions and skills. The more holistic emerging view of learning is captured in Schoenfeld's (1999. p. 6) definition: ' ... coming to understand things and developing increased capacities to do what one wants or needs to do ...'. Here learning is clearly portrayed as an ongoing process. We can further investigate the notion of learning as a process, by considering some influential metaphors that have been closely associated in the literature with the concept of learning.

\section{Learning Metaphors}

Sfard (1998) argued that two basic metaphors - learning as acquisition and as participation - have underpinned much educational thought. As the prominence of the learning as product view discussed earlier suggests, the acquisition metaphor has long been influential. It subordinates the process of learning to its products - the something acquired (knowledge, skills, attitudes, values, behaviour, understanding, etc). Sfard contrasts this metaphor with the increasingly influential participation one, claiming that neither metaphor by itself is adequate to understanding of the full complexities of learning. Certainly, the acquisition metaphor emphasises 
learning as a product and the 'folk theory' of a mind steadily accumulating stable, discrete substances or atoms. In contrast, it appears that the participation metaphor presents learning as either a product or a process. This is so because, while participation itself is a process, it appears that the learner comes to belong more and more to the community of practice by acquiring the right characteristics (products of learning).

An obvious question is whether Sfard's two metaphors exhaust the possibilities, or are there other significant learning metaphors that view learning as a process? Sfard does not mention other possible metaphors, but Elkjaer (2003), drawing on Dewey, suggests that inquiry is a more suitable metaphor for thinking about organisational learning. In support of the idea that inquiry is a more potent metaphor than acquisition, Elkjaer illuminatingly quotes Dewey:

..... thinking is a process of inquiry, of looking into things, of investigating. Acquiring is always secondary, and instrumental to the act of inquiring. It is seeking, a quest, for something that is not at hand.

(Dewey 1916, p. 148)

While being sympathetic to Elkjaer's Deweyan perspective, I maintain that an even better metaphor for capturing learning as a process is construction (or reconstruction). This is also a Deweyan idea, but is, I argue, superior to the inquiry metaphor for suggesting the rich scope of the changes that are implicated in Deweyan learning. The construction metaphor encapsulates the construction/re-construction of the learning, of the learner's self, and of the environment (world), which includes the self.

Thus, the argument is that the construction metaphor captures the various dimensions of change much better than participation or inquiry metaphors do. Even some well-known sociocultural theorists, whose work has brought the participation metaphor to prominence, seemingly recognise its limitations. For instance, Rogoff (1995) proposes viewing learning and development within a community in terms of three ".... inseparable, mutually constituting planes comprising activities that can become the focus of analysis at different times, but with the others necessarily remaining in the background of the analysis." (p. 139) The three planes of analysis are:

Apprenticeship (community/institutional)

Guided participation (interpersonal)

Participatory appropriation (personal)

It is the third of these that particularly involves construction processes, since appropriation of a personal kind clearly implies something stronger than mere replication. So Rogoff proposes that participation needs supplementation.

The three metaphors about learning link differently to lifelong learning and related concepts. As noted already, the acquisition metaphor has unattractive implications for lifelong learning, suggesting endless accumulation of discrete 
pieces of learning. As well, the focus here is firmly on the individual learner. By contrast, the participation metaphor is undoubtedly more congenial for lifelong learning. People participate in many activities at many levels, signalling much scope for learning. This learning is at whole person level rather than just being centred on the mind. As well, rather than focussing solely on individual learners, the participation metaphor accepts the importance of learning by groups, communities and organisations. Such learning that goes beyond individual learners appears to be an important dimension of much learning in workplaces. However, participation in itself does not ensure learning. Quite the opposite, as is demonstrated by participation in closed societies or organisations that are dedicated to resisting change (e.g. certain religious societies). The construction metaphor, however, with its tripartite focus on the construction of learning, of learners, and of the environments in which they operate, has a wider scope. One in which change, learning and human flourishing are inextricably enmeshed. So it seems that Sfard's two basic metaphors need expansion to include (re)construction as a third metaphor, that will enable learning at work and lifelong learning to receive proper attention.

\section{What Does the Preceding Mean for Workplace Learning?}

The main conclusion is, I trust, clear. Workplace learning is poorly understood if it is viewed as a product. Instead, there are considerable advantages in viewing it primarily as a process, one that incorporates important social, cultural, and political dimensions. Both work practices and the learning that accompanies them are processes. We might almost view practice as a process that coincides with learning. This process feature is also best captured by a (re)construction metaphor, given that the use of metaphor seems to be unavoidable when thinking about learning. It also seems that we should be wary of attempts to account for workplace learning in terms of single overriding factors or via universally applicable theories (see Hager 1999). So I conclude that four major criteria for assessing workplace learning theories are how well they:

- view such learning as a process

- take account of the social, cultural, and political dimensions

- reflect a (re)construction metaphor

- avoid single factor or universally applicable explanations

My current work involves an examination of various theories of workplace learning in terms of how well they exemplify these criteria (Hager forthcoming). In a previous OVAL seminar (Hager 2001) I proposed four dimensions for understanding productive learning:

1. productive learning re-defines existing patterns and rules.

2. productive learning involves the creation of new learning that simultaneously reshapes the environment in which the learning occurs. This reshaped environment includes the learner via 'autopoiesis', the 
organisation and the work practices. So the process and product of learning are inextricably linked.

3. productive learning involves the social, cultural and political construction of individual identities.

4. productive learning centres on holistic, whole person, embodied judgements.

The first two of these clearly exemplify the first three of the four major criteria for assessing workplace learning theories identified above. The third of these is itself one of the four major criteria. The holism of the first fourth of these resonates with the second and fourth of the four major criteria.

It will only be, I argue, in further explicating these kinds of relationships that we will gain better theoretical and practical understanding of workplace learning. In the process, we may even learn to think more creatively and productively about learning in all of its manifestations.

\section{References}

Altrichter H., Posch P. \& Somekh B. (1993) Teachers Investigate Their Work. London \& New York: Routledge.

Beckett D. \& Hager P. (2002) Life, Work and Learning: Practice in Postmodernity. Routledge International Studies in the Philosophy of Education 14. London and New York: Routledge.

Bereiter C. (2002) Education and Mind in the Knowledge Age. Mahwah, N.J./London: Lawrence Erlbaum Associates.

Boud D. \& Garrick J. (eds.) Understanding Learning at Work. London and New York: Routledge.

Boud \& Solomon (2004) "'I Don't Think I Am a Learner": Acts of Naming Learners at Work', Journal of Workplace Learning, Vol. 16, Nos. 1-2, (March issue in press).

Bourdieu P. (1990a) The Logic of Practice. Stanford: Stanford University Press.

Bourdieu, P. (1990b) In Other Words: Essays Towards a Reflexive Practice, Polity Press: Cambridge.

Bowden J. \& Marton F. (1998) The University of Learning. London: Kogan Page.

Brabazon T. (2002) Digital Hemlock: Internet Education and the Poisoning of Teaching. Sydney: University of New South Wales Press. 
Bransford J.D. \& Schwartz D.L. (1999) 'Rethinking Transfer: A Simple Proposal With Multiple Implications', Review of Research in Education, Vol 24, pp. 61-100.

Brown A.L. \& Palincsar A.S. (1989) 'Guided, cooperative learning and individual knowledge acquisition' in L.B. Resnick (ed.) Knowing, Learning and Instruction: Essays in Honour of Robert Glaser. Hillsdale, NJ: Lawrence Erlbaum, pp. 393-451.

Bruner J. (1996) The Culture of Education. Cambridge, Mass./London: Harvard, University Press.

Dewey J. (1916) Democracy and Education. New York: Macmillan.

Elkjaer B. (2003) 'Organizational Learning with a Pragmatic Slant', International Journal of Lifelong Education, Vol 22, No. 5, pp. 481-94.

Engestrom Y., Miettinen R. \& Punamaki R.-L. (1999) Perspectives on Activity Theory. New York: Cambridge University Press.

Engestrom Y. (2001) 'Expansive Learning at Work: Toward an Activity Theoretical Reconceptualization', Journal of Education and Work, Vol. 14, No. 1, pp. 133-56.

Hager P. (1999) 'Finding a Good Theory of Workplace Learning', in D. Boud \& J. Garrick (eds.) Understanding Learning at Work. London and New York: Routledge, pp. 65-82.

Hager P. (2001) 'Towards a Productive Conception of Productive Learning', Research in Adult and Vocational Learning Productive Learning Seminar Series, University of Technology, Sydney, 11 September 2001. (Available at www.oval.uts.edu.au)

Hager P. (forthcoming) 'Current Theories of Workplace Learning: A Critical Assessment' in International Handbook of Educational Policy.

Dordrecht/Boston/London: Kluwer Academic Publishers.

Illich, I. (1973), Deschooling Society, Penguin, Harmondsworth.

Lakoff G. \& Johnson M. (1980) Metaphors We Live By. Chicago: University of Chicago Press.

Lave J. \& Wenger E. (1991). Situated Learning: Legitimate peripheral participation. Cambridge: Cambridge University Press.

Lyotard J.F. (1984) The Postmodern Condition: A Report on Knowledge.

Manchester: Manchester University Press. 
Magee B. (1998) Confessions of a Philosopher. London: Phoenix.

Passmore J. (1980) The Philosophy of Teaching. London: Duckworth.

Polanyi M. (1983) The Tacit Dimension. Gloucester, MA: Peter Smith.

Prosser M. \& Trigwell K. (1999) Understanding Learning and Teaching: The Experience of Higher Education. Buckingham: Open University Press/Society for Research into Higher Education.

Rogoff B. (1995) 'Observing Sociocultural Activity on Three Planes:

Participatory Appropriation, Guided Participation, and Apprenticeship' in J.J. Wertsch, P. del Rio \& A. Alvarez Sociocultural Studies of Mind Cambridge: Cambridge University Press.

Schoenfeld A.H. (1999) 'Looking Toward the 21 ${ }^{\text {st }}$ Century: Challenges of Educational Theory and Practice', Educational Researcher, Vol. 28, No. 7, pp. 414.

Schön D.A. (1983) The Reflective Practitioner. New York: Basic Books.

Sfard A. (1998) 'On Two Metaphors for Learning and the Dangers of Choosing Just One', Educational Researcher, 27(2), 4-13.

Symes C. \& McIntyre J. (eds.) Working Knowledge: The New Vocationalism and Higher Education. Buckingham: Open University Press/Society for Research into Higher Education.

Usher R. \& Edwards R. (1994) Postmodernism and Education. London and New York: Routledge.

Wertsch J.V. (1998) Mind as Action. New York: Oxford University Press.

Winch C. (1998) The Philosophy of Human Learning. Routledge International Studies in the Philosophy of Education. London and New York: Routledge. 